\title{
Studies on Corrosion Test of Tinplate*
}

\author{
By Kinji SAIJO,** Hiroaki KAWAMURA,** Tadashi NEMOTO** and \\ Tsuneo INUI**
}

\begin{abstract}
Synopsis
The corrosion behavior of tinplate was investigated in acid food media correlated to ISV (iron solution value) and ATC value (alloy tin couple). The electrochemical potential of tin in ISV test solution was more positive than that of iron at low stannous ion concentration but with the increase of stannous ion concentration the galvanic-couple relation of tin and iron changes. ISV of tinplate is closely related to the corrosion rate of tinplate in air free acid media and also to the iron pick up in the solution where both potential of tin and iron are close.

The results of this study suggest that both ISV and ATC value are concerned in the galvanic attack of tinplate in spite of a little difference of their meanings.
\end{abstract}

\section{Introduction}

Tinplate is widely used for material of containers such as sanitary can and miscellaneous can because of its bright appearance and superior corrosion resistance against various contents. An excellent corrosion performance is especially required for sanitary can. For instance, for fish and meat cans, the resistance of tinplate against sulfide staining ${ }^{1,2)}$ is required, whereas for an acid fruit can, the demand for tinplate turns to the resistance against tin dissolution which affects the shelf life of can. For many years several property testing methods ${ }^{3-5)}$ have been available for manufacturers and users. The generally accepted tests to evaluate the corrosion resistance of tinplate in acid food media are the iron solution value test (ISV) and the alloy tin couple test (ATC). These tests have been conducted to select the tinplate which should provide the short shelf life can, when the tinplate is used for a severely corrosive product can.

Since continuous cast steel has been used for base steel of tinplate, it was investigated whether the corrosion resistance of the tinplate manufactured with continuous cast steel might be different from that manufactured with capped steel. $^{6-8)}$ It has been reported that the tinplate from capped steel showed lower ATG value than that from continuous cast steel, whereas the tinplate from continuous cast steel showed lower ISV than that from capped steel. Both indications have been accepted as the parameters which represent the corrosion resistance of tinplate in acid food media. It has been considered that the difference in tendency of these parameters between continuous cast steel and capped steel is due to the nature of these steel substrate.

Since recent developments of surface analytical techniques enable to investigate the surface cleanness of steel substrate, the progress of the studies concerning these differences has been achieved to some extent but there are still many unclear facts.

It has been revealed that the surface species, such as oxide films and inclusions, play an important role in corrosion behavior of tinplate. It was also reported that the ISV and the ATC value were significantly influenced by enriched oxides on surface which were formed during annealing. The other investigation showed that the amount of surface inclusions over the capped steel surface mainly affected the ISV because the surface inclusions introduced pores in tin layer.

Generally it is considered that the ISV indicates the porosity of surface tin layer whereas the ATC value indicates the porosity of iron tin alloy layer. Both values have been adopted as parameters to estimate the shelf life of the acid fruit can. The difference between capped steel and continuous cast steel in the tendency of these parameters is inconvenient to produce and use tinplate for can materials. Which value should be adopted to produce the tinplate having an excellent corrosion resistance is an important and serious problem for not only steel makers but also can makers.

The present investigation was made in order to clarify the electrochemical meanings of the iron solution test (ISV test) and to understand the relationship between the ISV and the corrosion resistance of tinplate in acid food media.

\section{Experimental}

\section{Materials}

The cold-rolled capped steel, aluminum-killed steel and silicon-killed steel of $0.24 \mathrm{~mm}$ in thickness were used for the substrate of tinplate. These steel sheets were electroplated with 5.6 or $11.2 \mathrm{~g} / \mathrm{m}^{2}$ of tin in a conventional acid stannous bath and flowbrightened by conduction heating. The electrochemical behavior of a pure tin sheet of $99.99 \%$ in purity and a cold-rolled capped steel sheet were also investigated.

\section{The Iron Solution Test (ISV test)}

The iron solution test was conducted by Willy's method. Before measurement, flat 4 in. $^{2}$ discs of tinplate were cathodically cleaned in $0.5 \%$ sodium carbonate solution at $1.5 \mathrm{~A}$ for $30 \mathrm{sec}$, rinsed with water and dried in acetone vapor. The specimens were placed inside the Bakelite caps of a $8 \mathrm{oz}$. tall wide mouth bottle and held in place with 2 in. diameter gaskets.

* Presented to the 99th ISIJ Meeting, April 1980, at The University of Tokyo in Tokyo. Manuscript received July 7, 1980.

** Technical Research Laboratory, Toyo Kohan Co., Ltd., Nagahama, Higashitoyoi, Kudamatsu 744. 
The test was made by adding successively to the bottle $23 \mathrm{ml}$ of $2.18 \mathrm{~N}$ sulfuric acid, $2 \mathrm{ml}$ of $3 \%$ hydrogen peroxide and $25 \mathrm{~m} l$ of a $40 \mathrm{~g} / l$ solution of ammonium thiocyanate. After the cap with the specimen was screwed on tightly, the assembly was inverted and allowed to stand for experimental period at $26.7 \pm 2.8^{\circ} \mathrm{C}$ without agitation. At the end of this period, the vessel was placed upright, and the cap with specimen was quickly removed and $1 \mathrm{~m} l$ of $3 \%$ hydrogen peroxide was added. The dissolved iron and tin were measured by atomic absorption spectrometry.

The alloy tin couple test (ATC test) was also conducted by G. G. Kamm and A. R. Willy's method. The surface free tin layer of the tinplate specimen was removed by anodic dissolution in a sodium hydroxide electrolyte. Then the specimen having a $3.6 \mathrm{~cm}^{2}$ region sealed by PVG (Poly Vinyl Chloride) tape and paraffin were set in the glass cell, filled with a deaerated grapefruit juice with $100 \mathrm{ppm}$ of stannous ion. After $24 \mathrm{hr}$ at $26^{\circ} \mathrm{C}$, the couple current between specimen and pure tin was measured.

\section{Corrosion Test in Acid Food Media}

The corrosion behavior of tinplate whose ISV was known, was also investigated in some food media. The commercial tomato paste, tomato juice and apple juice were used as the corrodents in this study.

A test was made by adding the tomato paste solution, which was prepared by mixing an equal amount of deionized water and tomato paste, to the glass cell in vacuum chamber at $40 \mathrm{mmHg}$. The tinplate specimens with $1 \mathrm{~cm}^{2}$ of exposed window sealed in the same manner were immersed in a corrodent with a saturated calomel electrode as a reference electrode and a platinum electrode. The specimen potential (vs. SCE) and the corrosion current density were measured at room temperature. The period for required the complete dissolution of surface free tin layer was determined by measuring the change in potential from tin to iron.

The corrosion current densities of tinplate specimen in a tomato juice were measured under air free and air saturated condition to study the effect of dissolved oxygen on the corrosion current of tinplate.

The correlation between the ISV and the iron dissolution of tinplate specimen in apple juice was also examined. In this test two specimens, which were masked by PVG tape with $1 \mathrm{~cm}^{2}$ of exposed window and sealed with paraffin, were immersed in a PVG cell which contained $250 \mathrm{ml}$ of apple juice. The PVG cell, in which specimens were immersed, were set in a vacuum chamber where the total gas pressure was below $40 \mathrm{mmHg}$. After the chamber was stored at room temperature for 60 days without agitation, the dissolved iron in the apple juice was measured by means of atomic absorption spectrometry.

In this study, the corrosion current densities were measured by the polarization conductance method. ${ }^{9)}$ When a specimen with $1 \mathrm{~cm}^{2}$ of exposed area, which had been immersed in a given solution, was polarized within the range of $10 \mathrm{mV}$ from the corrosion potential, the corrosion current was calculated by following equation;

$$
\begin{aligned}
\left(\frac{d E}{d I}\right)_{E_{\mathrm{corr} .}} & =R \ldots \ldots \ldots \ldots \ldots \ldots \ldots \ldots \ldots \ldots \ldots \ldots \ldots \ldots \\
R & =\beta_{c} \times \beta_{a} / I_{\mathrm{corr} .} \times\left(\beta_{c}+\beta_{a}\right)
\end{aligned}
$$

where, $d E$ : an applied potential

$d I$ : the amount of increased corrosion current density

$E_{\text {corr. }}$ : the corrosion potential of the specimen

$I_{\text {corr. }}$ : the corrosion current density of the specimen

$\beta_{c}, \beta_{a}$ : the Tafel slopes of cathodic and anodic partial polarization curves, respectively.

\section{Results and Discussion}

\section{Potential of Iron and Tin in the ISV Test Solution}

The changes in corrosion potential and dissolution behavior of tin and iron were investigated in the solution of the ISV test to reveal the meaning of the ISV parameter.

The effect of stannous ion concentration in the solution on the corrosion potentials of tin and iron are shown in Fig. 1. At low stannous ion concentration, the potential of tin was more noble than that of iron. With increase of stannous ion concentration both potentials shifted to more noble potentials although the potential change of iron observed was larger than that of tin. At $100 \mathrm{ppm}$ of stannous ion concentration, both potentials became approximately equivalent and further increase of the concentration made the potential of iron more noble than that of tin. It suggests that at the initial stage of the corrosion the surface tin layer of tinplate dissolves and the iron which is exposed to the solution through pores of tin layer is also simultaneously dissolved while protecting the surrounding tin cathodically. When the concentration of stannous ion in the neighborhood of tinplate surface increases more than $100 \mathrm{ppm}$, the galvanic interaction between the surface tin and iron substrate is estimated to change so that the exposed iron surbstrate is cathodically protected consequently.

As shown in Fig. 1, iron and tin exhibited the

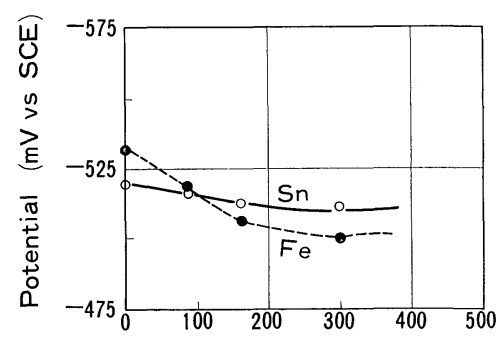

Concentration of $\mathrm{Sn}(\mathrm{ppm})$

Fig. 1. Effects of stannous ion concentration on corrosion potential of tin and iron in the ISV test solution at room temperature. 
potentials between $-500 \mathrm{mV}$ and $-530 \mathrm{mV}$ (vs. SCE) in the ISV test solution. These potentials were somewhat noble to those in acid food media. It can be considered that the potential of iron in the ISV test solution, in which the potential became noble with increase of the stannous ion, might be influenced by the deposition or adsorption of stannous ion on the surface of iron electrode.

\section{Dissolution Behavior of $T$ in and Iron from Tinplate in the ISV Test Solution}

The ISV is appreciated by the amount of dissolved iron from tinplate after $2 \mathrm{hr}$ in tightly closed bottle in which an oxidizing agent is introduced to an acid solution.

The typical changes in the amount of dissolved iron are shown in Fig. 2. One group is a typical example of tinplate whose iron dissolution is completely restrained after $30 \mathrm{~min}$ and the other exhibits a continuous increase of dissolved iron up to $2 \mathrm{hr}$. On the former type, the exposed iron could be cathodically protected by surrounding tin because the increase of dissolved stannous ion results in the reversion of galvanic interaction between iron and tin at the pore where the exposed iron dissolves anodically at low stannous ion concentration. In contrast to the former, iron, in the latter case, dissolves continuously without restraint due to stannous ion. Although the remarkable increase of exposed substrate was observed, the rate of iron dissolution was approximately constant during testing period. This fact suggests that the iron dissolution occurs at a limited area, such as the initial pores of surface tin layer. On the latter, it is probable that the dissolved stannous ion could not inhibit iron dissolution effectively.

Generally, most of conventional tinplates have low ISV and belong to the former type of corrosion behavior. On the other hand, the tinplate used for the can which induces hydrogen swell has been of the latter type. The ISV test was carried out in a closed vessel which contained the test solution with hydrogen peroxide as an oxidizing agent. The tinplate specimen was placed at the bottom end of vessel without agitation during the whole test period. Under this condition, the dissolved oxygen in the solution is consumed and reduced near the surface of the specimen by the corrosion of tin and iron. From the result shown in Fig. 1, it was expected that the tin layer and iron substrate at pores ${ }^{10,11)}$ should corrode rapidly at the initial stage of the test, then the iron dissolution should be more or less restrained by the increase of stannous ion and the consumption of dissolved oxygen as the progress of tin corrosion. Actually, in the case of normal tinplate, the iron dissolution was completely restrained after $30 \mathrm{~min}$ as shown in Fig. 2.

From the result in Fig. 2, it can be seen that complete restraint of iron dissolution after $30 \mathrm{~min}$ probably influence the tin dissolution. Then the relation between the ISV and the ratio of the amount of dissolved tin after $2 \mathrm{hr}$ to that after $30 \mathrm{~min}$ was examined. The result was shown in Fig. 3. In the case of tinplate having low ISV, the amount of stannous ion dissolved increased slightly by another $1 \mathrm{hr}$ and a half immersion. But the ratio of dissolved tin increased with the increase of the ISV. The result showed that the iron dissolution of tinplate having high ISV could not be restrained during testing period in spite of a remarkable increase of stannous ion. Photograph 1 shows the scanning electron micrographs of the tinplate surface corroded in the ISV test solution. An appreciable amount of area of exposed iron-tin alloy layer was observed on the surface. In the case of the tinplate having low ISV, the exposed alloy layer usually does not have special defects. At the exposed alloy layer, the iron substrate was slightly attacked although the coverage of alloy layer was insufficient. The substrate which was exposed by the localized attack of tin layer did not contribute to the iron dissolution. Contrary to the low ISV specimen, the pits where the surface tin layer remained around were frequently observed in the high ISV specimen. The pattern of pits indicated that the substrate at the pore continued to dissolve anodically without the protection by the dissolved stannous ion. The tinplate having many such defects exhibited high ISV. The surface tin did not always remain around all pits, but around the pits of the specimen with high ISV,

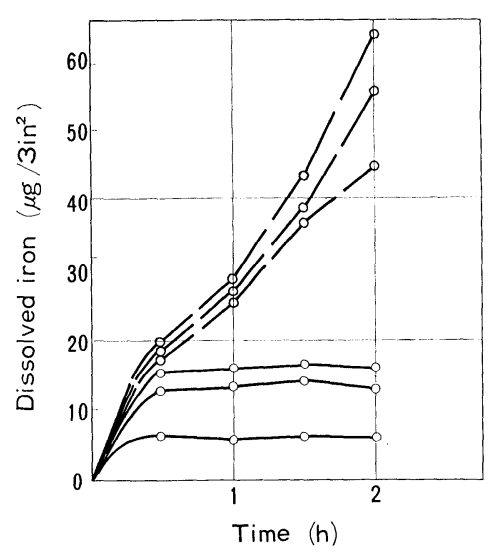

Fig. 2. The dissolved iron of tinplate during ISV test.

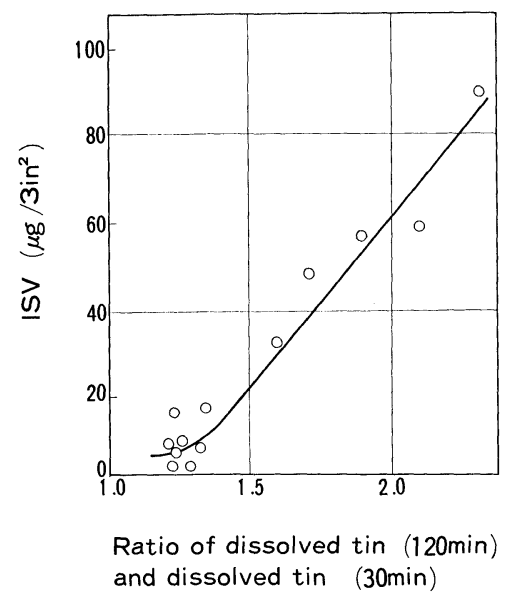

Fig. 3. Relationship between ISV and the ratio of amount of tin dissolved during 120 and $30 \mathrm{~min}$ in ISV test solution. 

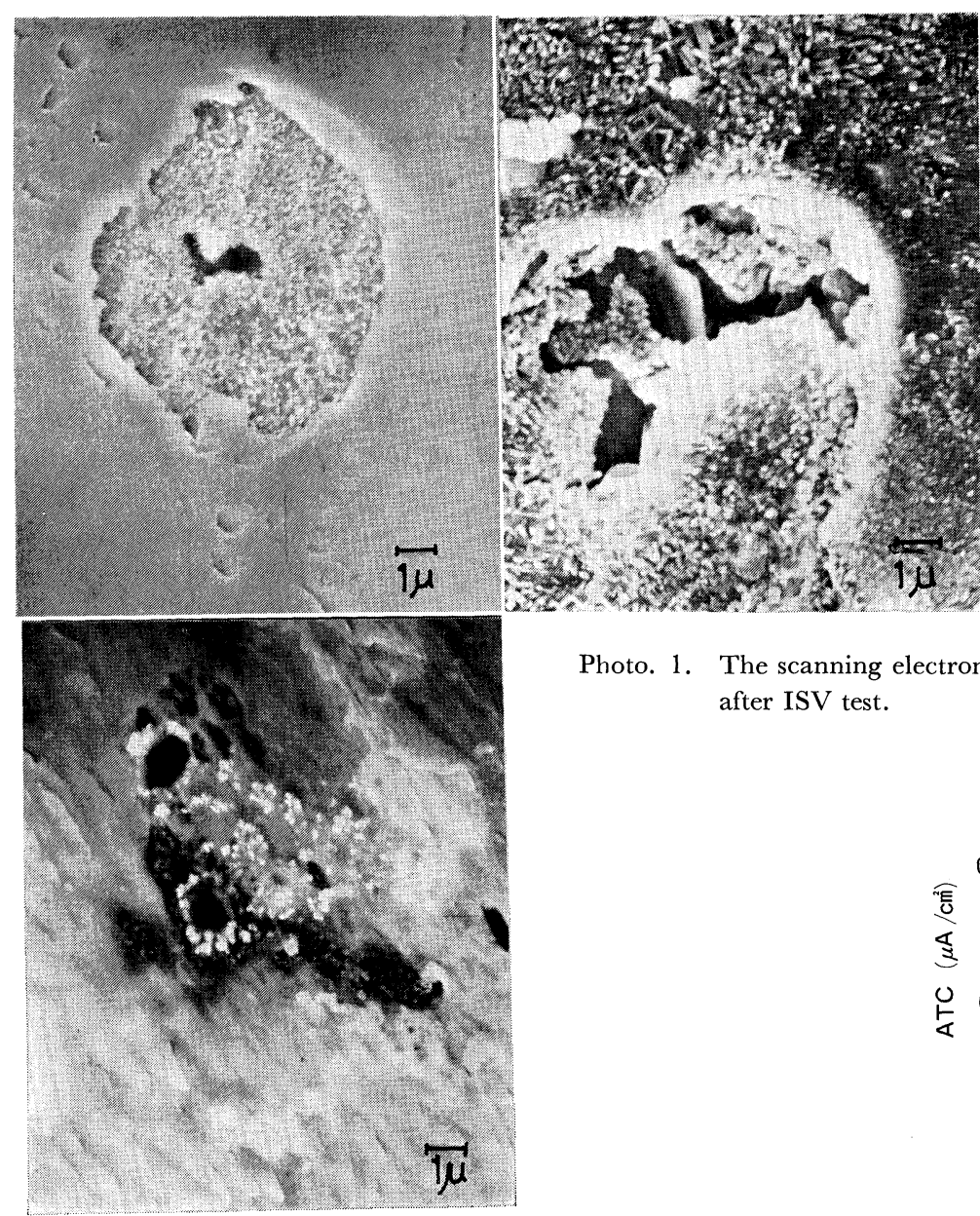

Photo. 1. The scanning electron micrographs of tinplate specimen after ISV test.

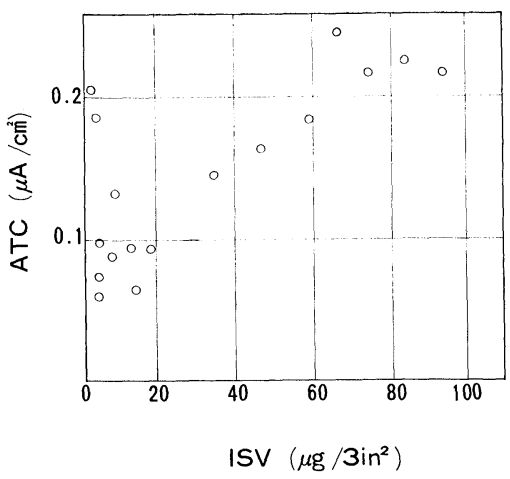

Fig. 4. Relationship between ATC value and ISV of various tinplates.

pores which could be cathodes. The shape of the defect, particularly its depth, is also considered to contribute to the change of the role of defect. Furthermore, as reported recently, the amount and composition of surface constituents, which segregate to the steel surface during annealing, affect the potential of steel substrate in a solution. Therefore, it is estimated that these factors might also contribute to the change of the role in corrosion to some extent.

Both iron and tin tend to dissolve to a considerable amount when the high ISV tinplate is immersed in the ISV test solution. The alloy layer is widely exposed to the solution during the ISV test due to the dissolution of surface tin layer so that the ISV is expected to be influenced by the structure of alloy layer. The ATG value is well known to indicate the porosity of alloy layer. The relationship between the ATG values and the ISV is shown in Fig. 4. The high ISV specimen shows high ATG value, but the low ISV specimen is not always limited to show low ATG value. Even if the ATG value was improved by increasing the amount of alloy layer, the ISV was only slightly decreased. The decrease of the amount of alloy causes high ATG value by its poor coverage but it did not necessarily lead to high ISV because of the difference of test procedure. In the case of the ISV test, the iron substrate exposed 
by the dissolution of surface tin layer could be protected by dissolved stannous ion, even if the substrate was poorly covered by a defect-free alloy layer. On the other hand, if the solution contained the stannous ion enough to inhibit the exposed substrate, the ATG value could not represent the porosity of alloy layer.

\section{Corrosion of Tinplate in Some Food Media}

The corrosion behavior of tinplate in some food media was examined by the ISV test. The relationship between the corrosion current density of tinplate in a tomato juice and the ISV is shown in Fig. 5. Figure 5(a) shows the result which was measured in the juice deaerated by pure nitrogen, while Fig. 5(b) shows the result obtained in an air saturated juice. The corrosion current density correlated to the ISV in the air saturated juice did not change so much as the case of deaerated condition, and the former corrosion current density was 20 to 40 times as much as that in the air free juice. In the deaerated juice, an obvious correlation was observed between the ISV and the corrosion current density of tinplate. The ISV in this case was $60 \mu \mathrm{g} / 3$ in. ${ }^{2}$, which was 2 to 3 times as much as low ISV tinplate. It suggests that the ISV has a correlation with the corrosion rate of tin layer after dissolved oxygen is consumed.

As shown in Fig. 6, the period required for consumption of surface tin layer on tinplate depends on its ISV. This result was obtained in a tomato paste with the tinplate whose tin coating weight was $5.6 \mathrm{~g} / \mathrm{m}^{2}$. The period for consumption of surface tin layer was obtained by measuring the potential change of the specimen from tin to iron potential. There is obvious correlation between the period and the ISV. The period of the tinplate, whose ISV was below $20 \mu \mathrm{g} / 3$ in. ${ }^{2}$, was 2 to 3 times longer than that of the tinplate whose ISV was $60 \mu \mathrm{g} / 3$ in. ${ }^{2}$. Generally the shelf life of the acid food can depends mainly on the corrosion rate of surface tin layer. Therefore the ISV is expected to be a suitable indicator to predict the shelf life of the acid food can because of its good cor-

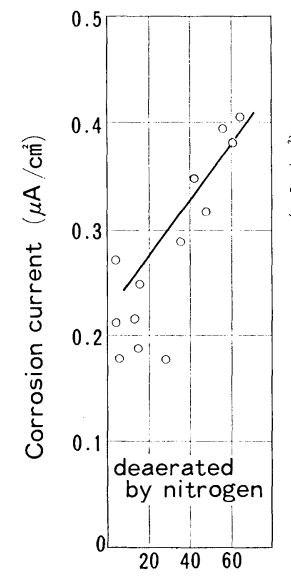

ISV $\left(\mu \mathrm{g} / 3 \mathrm{in}^{2}\right)$

(a) Deaerated juice

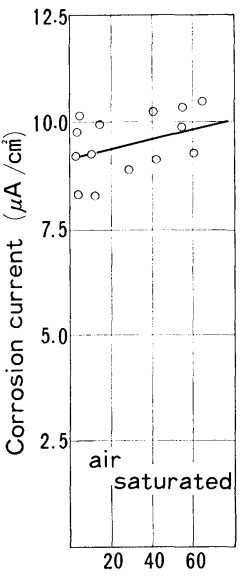

ISV $\left(\mu \mathrm{g} / 3 \mathrm{in}^{2}\right)$

(b) Air saturated jice
Fig. 5. Relationship between ISV and corrosion current of tinplate in tomato juice at room temperature relation with the consumption period of surface tin layer. It is certain that the shelf life of can is controlled not only by the corrosion of surface tin layer but also by the corrosion of iron substrate. It is sure that the corrosion of surface tin plays a main role in the corrosion of the acid food can. Because the corrosion rate of tin layer on tinplate depends mainly on the galvanic couple between surface tin and iron substrate in acid food media, the result shown in Fig. 6 suggests that the ISV represents the activity of cathodic reaction.

Figure 7 shows the relationship between the ISV and the amount of the dissolved iron in an apple juice after 60 days at room temperature. The amount of dissolved iron was about $40 \mu \mathrm{g} / 2 \mathrm{~cm}^{2}$ in the ISV range below $20 \mu \mathrm{g} / 3$ in. $^{2}$ and it increased in proportion to the ISV. In this apple juice the potential difference between tin and iron was about $35 \mathrm{mV}$ and it was rather smaller than that in the tomato juice. The corrosion current density of iron substrate in this juice was considerably larger than that in the tomato juice. In such solution the iron substrate could not be ex-

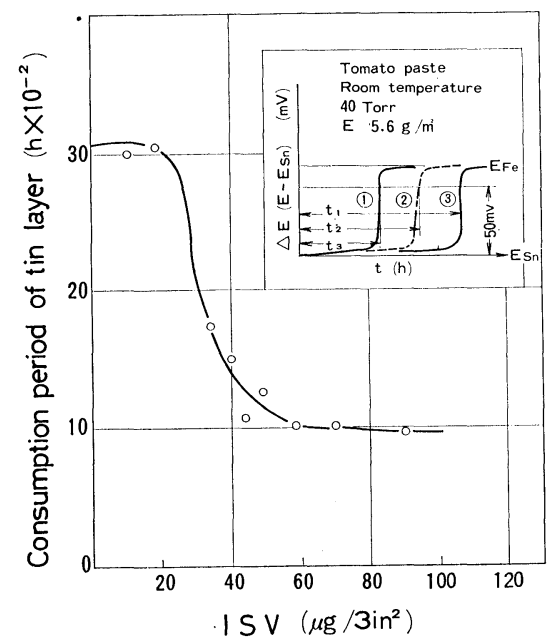

Fig. 6. Relationship between ISV and the period for consumption of surface tin layer in diluted tomato paste solution.

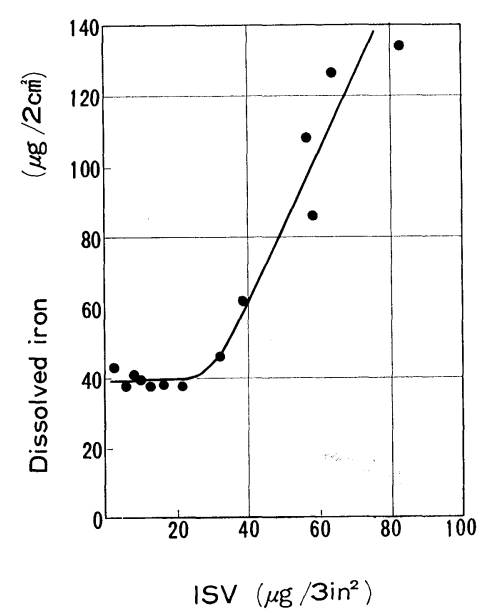

Fig. 7. Relationship between ISV and the iron pick up in evacuated apple juice of $400 \mathrm{mmHg}$ after 60 days at room temperature. 
pected to be sufficiently protected cathodically by surface tin so that the simultaneous dissolution of tin and iron might continue. However the amount of dissolved iron in this solution shows an obvious correlation with the ISV. It suggests that the iron dissolution in this solution should take place in the same manner in the ISV test solution.

The scanning electron micrographs in Photo. 2 are the corroded surface in a mandarin orange and a tomato paste in which the iron substrate should be cathodically protected by the surface tin. The photomicrograph shows the similar pattern to that observed after the ISV test. As shown in Photo. 2 (b), the area where the surface tin might be cathodically protected by iron dissolution and remain near by the exposed iron was observed. Of course the region, where the alloy layer was exposed by the dissolution of surface tin but the iron substrate was prevented from dissolution, was also observed frequently (Photo. 2 (a)).

As described above, the corrosion behavior of tinplate in acid food media seems to be quite similar to that in the ISV test solution. Therefore the ISV could well be used to represent the corrosion resistance of tinplate in acid food media. Both photomicrographs suggest that the iron substrate can act both as anodic and cathodic in the same solution. It also suggests that the stannous ion in the solution plays a very important role in forming a galvanic cell of tin and steel substrate. ${ }^{12,13)}$ The galvanic interrelation between tin and iron substrate depends on the concentration of stannous ion because both potentials of tin and iron depend on the stannous ion concentration as shown in Fig. 1. From these considerations, it is certain that the test method of corrosion resistance for tinplate should be affected by stannous ion. The results obtained in this study suggest that the ISV is a suitable indication for the corrosion resistance of tinplate in acid food media. However, at low ISV range it is uncertain that the ISV could represent the corrosion resistance actually.

\section{Discussion on the Corrosion Behavior of Tinplate (Mainly in Acid Food Can)}

The corrosion behavior of tinplate in acid food can is strongly affected by the nature of canned food, additional agent, etc., and even in the same kind of food products a different behavior is often observed depending on the district of harvest of canned food. The general characteristics observed on tinplate for acid food can are as follows. ${ }^{14)}$ The iron substrate is cathodically protected by a sacrificial dissolution of surface tin layer because the potential of iron is more noble than that of tin in acid food media. Corresponding to the anodic dissolution of surface tin layer, the cathodic reaction is slightly accompanied by the hydrogen evolution. It is considered that the hydrogen swell, which determines the shelf life of can, is due to the cathodic reaction accompanied with the dissolution of iron substrate. In a can the corrosion of surface tin is restrained by the consumption of dissolved oxygen and the increase of stannous ion. The dissolution of tin in the can is dominated at the initial stage by the concentration of dissolved oxygen. As described in previous section, it is certain that tin dissolution after consuming the dissolved oxygen should be controlled by the amount of active cathodic sites such as a failure of alloy layer.

Corrosion process can be divided generally into two processes according to the nature of cathodic reaction. One is controlled by the reduction of residual oxygen which is unavoidable at packing process. This process is considered to control the corrosion rate at the initial stage but it might be rapidly restrained by the consumption of dissolved oxygen because the amount of dissolved oxygen is estimated to be considerably small. Another process is controlled by the cathodic reaction concerning the deposition from stannous ion as described by Sherlock. ${ }^{15}$ ) This reaction is significantly affected by the amount of active cathodic sites which increase with the exposed area of iron substrate.

Since the reversible potential of tin electrode is written as, ${ }^{16)}$

$$
\begin{aligned}
\mathrm{Sn} & =\mathrm{Sn}^{2+}+2 e^{-} \quad \ldots \ldots \ldots \ldots \ldots \ldots \ldots \ldots \\
E & =-0.39+0.0295 \log a_{\mathrm{Sn}^{2+}}
\end{aligned}
$$

the corrosion potential of tin in acid food media is within the range of -550 to $-600 \mathrm{mV}$ (vs., SCE). As reported by Asano et al., ${ }^{12)}$ hydrogen scarcely

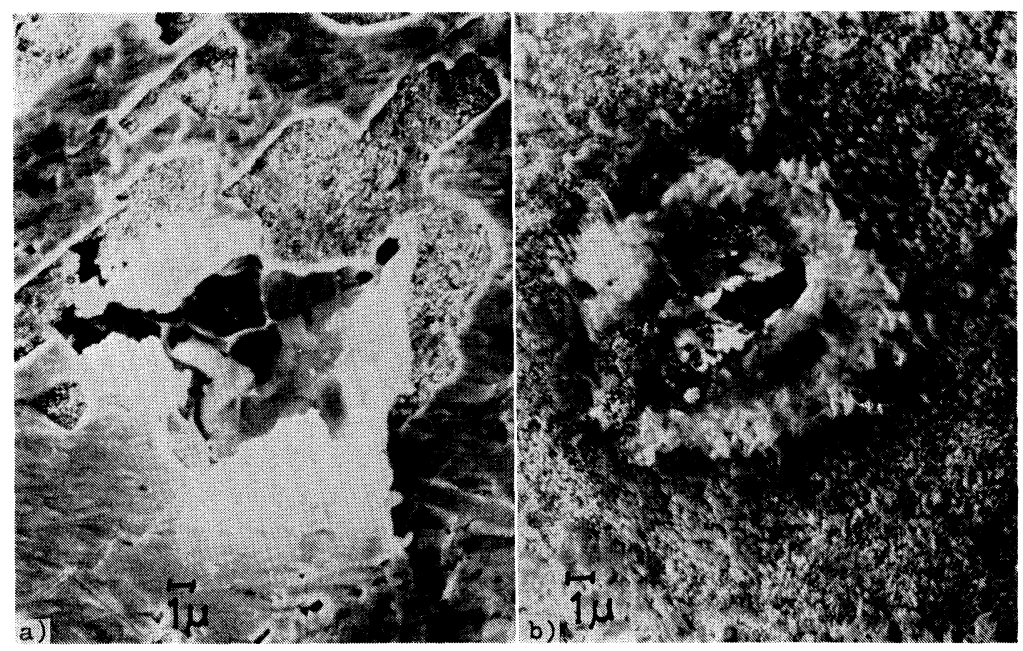

Photo. 2.

The scanning electron micrographs of tinplate can wall surface corroded in mandarin orange a) and tomato paste $b$ ). 
evolve at this potential where the surface tin remains on tinplate.

Recently the lacquered tinplate has been widely used for cans even for some acid food cans. Many experiments reveal that the corrosion of lacquered tinplate is originated from the failure of lacquer film such as pores and scratches which are formed during can manufacturing process or the handling process. However all of the cans, which have failures of lacquer film, do not always corrode abnormally. The progress of the corrosion of lacquered tinplate depend on the nature of tinplate even if the lacquer film has failures in it.

The controlling process of the corrosion of tinplate is considered to be the cathodic reaction so that the corrosion rate increases in proportion to the amount of active cathodic sites. The corrosion current of lacquered tinplate at scratched area could be explained by the galvanic couple of the exposed substrate and surface tin. Then the change of exposed area of substrate $(d A)$ per unit length of scratch in lacquered tinplate with time is givenas;

$$
d A=\frac{M}{z F \rho \delta} i d t
$$

where; $i$ : the corrosion current

$M:$ the atomic weight of tin

$\mathrm{z}$ : the valence of tin

F: Faraday constant

$\rho:$ the density of tin

$\delta$ : the coating thickness of surface tin layer. Then the exposure of the substrate results in an increase of corrosion current at the failure. The change in the corrosion current $(d i)$ in infinitesimal time $(d t)$ is given as follows, because the corrosion current should increase in proportion to the exposed area.

$$
\begin{gathered}
d i=\alpha \cdot \beta i d t \\
\beta=\frac{M}{z F \rho \delta},
\end{gathered}
$$

where $\alpha$ is the change in corrosion current by the exposure of unit area of substrate and is given as the current density. The $\alpha$ value corresponds to the ATC value at $100 \mathrm{ppm}$ of stannous ion concentration in grapefruit juice. From Eq. (3), the corrosion current $(i)$ is expressed as follows.

$$
i=i_{0} \exp (\alpha \cdot \beta t)
$$

The equation indicates that both the couple current between tin and substrate and the coating thickness of tin layer affect the progress of corrosion of lacquered tinplate significantly. In Eq. (4), $\alpha$ is given as the couple current density corresponding to the cathode controlled couple cell such as the ATC value. But the ATC value is the couple current when the tin anode has sufficiently large area comparing with the substrate cathode which covered with iron tin alloy layer. In the case of lacquered tinplate, the tin anode is considerably small in comparison with the cathode of exposed substrate whose area increases with the progress of corrosion. Since tinplate was used as lacquered can, the weight of tin coating has been reduced as low as possible. When the shelf life of can is estimated by the asumption based on the consideration that the shelf life of can should be determined by the consumption of surface tin layer. Equation (4) suggests that, to obtain the same shelf life can with a half tin coating tinplate, the $\alpha$ should be reduced to a half value comparing with the conventional tinplate.

As shown in Figs. 4 and 6, both the ATG value and the ISV may not stand for completely the susceptibility of galvanic attack of can. At high ISV range, the ISV could represent the corrosion performance of tinplate. However this could not be expected at low ISV range. Figure 8 shows the changes in the amount of dissolved iron and tin with time on the tinplates with different ATG value in the ISV test solution. In this case the specimen with high ATG value exhibited somewhat lower ISV than that with low ATG value, although the amount of dissolved tin of both specimens were close after $2 \mathrm{hr}$. After $50 \mathrm{hr}$ immersion the amount of dissolved iron from low ISV specimen became higher than that from high ISV specimen. The tin dissolution of high ATG value specimen was also promoted at that period. It suggests that, when the amount of exposed alloy layer increases to certain extent, the exposed substrate also affects the dissolution of tin and iron after long time immersion, although the exposed area is certainly protected by stannous ion. This is the reason why the accurate evaluation is difficult for low ISV tinplate. As mentioned in the previous section, the ISV test has an advantage and a disadvantage depending on samples.

In the case of lacquered can, the dissolution rate of tin could be estimated approximately by using Eq. (4). For the accurate presumption of the rate, it is necessary to obtain the accurate couple current $(\alpha)$ in the corrodent. The couple current of the alloy layer should be measured in the solution which contained more stannous ion than the ATG test solution, by coupling smaller tin anode than that of the ATC test. Of course the corrosion resistance of tinplate cannot be explained only by galvanic attack. The corrosion of surface tin layer is significantly influenced

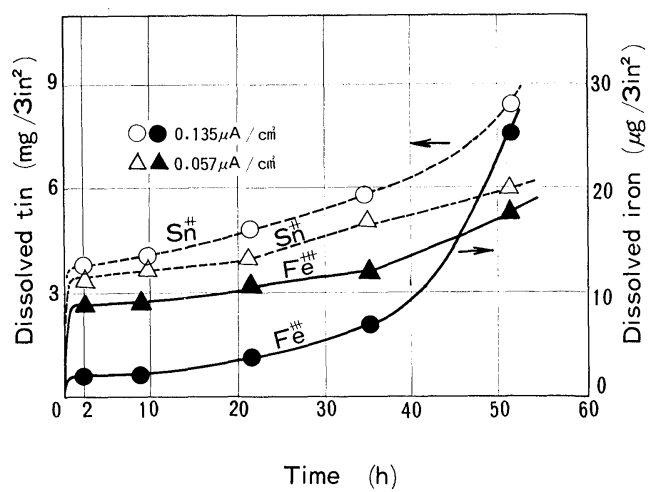

Fig. 8. Changes in the amount of dissolved tin and iron of tinplate with different ATG values in the ISV test solution for $50 \mathrm{hr}$ at ISV test temperature. 
by the surface constituents such as tin oxide and the CDC passive film. The corrosion resistance of lacquered tinplate should be significantly affected by the galvanic couple current, although the effect of the surface constituents should not be neglected. The results obtained in this study suggest that the couple current should be measured in the solution containing more stannous ion to evaluate the corrosion resistance of tinplate especially for the lacquered tinplate. Concerning the conventional tests such as the ISV and the ATG test, the ISV test is available to select the tinplate whose shelf life is considerably short.

Recently, the more the tendency of resorces and energy saving becomes of great concern a tin coating technique with less material is necessary. To reduce the coating weight without trouble, the new test methods, which reveal the galvanic attack in tinplate can and predict the shelf life exactly, are required in addition to the ATC and the ISV test.

\section{Conclusions}

(1) ISV test gives not only the indication of porosity of surface tin layer but also the activity of cathodic reaction for galvanic attack of tinplate and is a suitable test for screening the tinplate whose shelf life is considerably short.

(2) In ISV test solution, the galvanic interrelation between tin and iron substrate was reversed with the increase of stannous ion concentration. The potential of tin was more noble than that of iron at low stannous ion concentration but the potential of iron became more noble than that of tin above $100 \mathrm{ppm}$.

(3) On the surface of the tinplate specimens corroded in either ISV test solution or mandarin orange, the area where the surface tin layer was cathodically protected by exposed substrate was observed.

This suggests that the exposed substrate is not necessary in these media. The potential shift of iron substrate plays an important role in the reversion of galvanic interrelation.

\section{REFERENCES}

1) W. Andrae: Die Nahung, 13 (1969), 549.

2) S. E. Rauch and R. N. Steinbicker: Plating, 62 (1975), 246.

3) G. G. Kamm, A. R. Willey, R. E. Beese and J. L. Krickl: Corrosion, 17 (1961), 84t.

4) G. G. Kamm, A. R. Willey and R. E. Beese: Corrosion, 17 (1961), $72 \mathrm{t}$.

5) A. R. Willey, J. L. Krickl and R. R. Hartwell: Corrosion, 12 (1956), 23.

6) T. Jyanome, T. Hara, I. Matsushima, H. Takano and S. Kanbara: Tetsu-to-Hagané, 66 (1980), A85.

7) H. Moriyama, O. Yoshioka, H. Kawamura, K. Saijo, T. Inui and N. Tsutsui: Tetsu-to-Hagané, 66 (1980), A89.

8) K. Mochizuki, T. Ban and S. Harada: Tetsu-to-Hagané, 66 (1980), A93.

9) M. Stern and A. L. Geary: J. Electrochem. Soc., 104 (1957), 56.

10) H. Morimoto: Technical Reports of Toyo Kohan, 1 (1952), 74.

11) T. Ando and H. Morimoto: Toyo Kohan, 6 (1957), 31.

12) K. Wada, H. Asano, K. Kanechika and T. Nishihara: Corrosion Engineering, 11 (1962), 49.

13) J. G. Sherlock and S. C. Britton: Brit. Corros. J., 7 (1972), 180.

14) A. R. Willey: Brit. Corros. J., 7 (1972), 29.

15) J. C. Sherlock: Brit. Corros. J., 10 (1975), 144.

16) M. Pourbaix: Atlas of Electrochemical Equilibria in Aqueous Solutions, Pergamon Press, London, (1966), 475. 